\title{
Men of Movember and Their Motivations
}

Rebecca Cheung (University of British Columbia)

News Reporter - HSI 2OIO-2OII

Hairstyles tend to go in and out of style, but men can't go wrong with a mustache - at least during November. It's all part of "Movember", an annual global campaign aimed at raising money and awareness for men's health, specifically men's cancers, through masses of mustachioed men.

The concept is simple - clean-shaven men agree to put down their razors for the month of November and grow out their facial hair. Throughout the month, these hairy men collect donations, which typically benefit organizations supporting prostate cancer research and associated support programs.

Donations collected from the Movember Foundation in Canada benefit the Prostate Cancer Canada (PCC), which uses the funds to develop initiatives like the Clinician Scientist Award (a 2-year grant, totaling $\$ 300,000$, that is awarded to promising Canadian prostate cancer researchers) as well as expanding public education and awareness services.

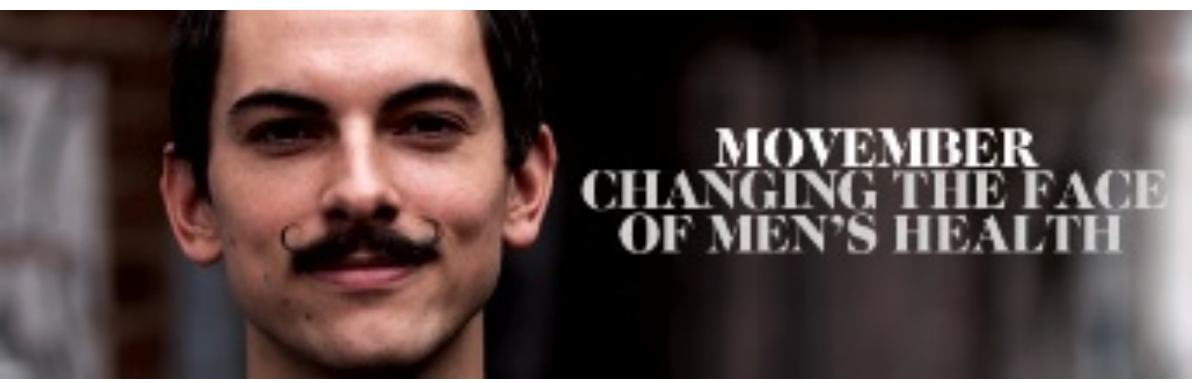

Since Movember's humble beginnings 8 years ago in Australia, the project has not only expanded geographically (in 2009, more than 250,000 Movember participants and supporters from all over the world raised over $\$ 47$ million), but also in meaning. Women who agree to stop shaving and waxing for the month have also been invited to participate. In addition, several individual fundraisers have opted to support other male cancer organizations, such as those promoting testicular cancer research.

\section{Making men's health a priority}

Despite these variations, for the most part, Movember's central message to raise funds for and awareness of men's health issues has remained consistent. It's the reason Movember participants like Michael Muthukrishna participated in the event last year. Muthukrishna, who grew a beard for Movember, joined up with other UBC students to raise money as a group.

"I think a lot of women's health issues, especially, in terms of breast cancer, has a big profile," Muthukrishna said. "Prostate cancer has a much, much smaller footprint."

Prostate cancer continues to be a concern for Canadian men. Last year, there were approximately 24, 600 new cases. Each week in Canada, approximately 470 men are diagnosed with prostate cancer and 80 men die from the disease, according to the Canadian Cancer Society website.

\section{Bringing men together}

Movember is also an effective way of building a sense of community among men. For instance, Timothy Shah, a graduate student at UBC, was inspired to grow his moustache after his classmates and friends circulated emails encouraging him to participate.

"This is my first year doing [Movember] because I was in a more supportive environment," said Shah. "There were a bunch of guys, some guys were actually doing it for the first time too. We did it together, in spite of how bad we looked."

Shah organized a Movember ping-pong tournament at his residence hall, raising over $\$ 100$ from participants and spectators. He also collected about $\$ 60$ from friends and family throughout the month.

Besides bonding over facial hair, Shah believes that Movember's significance lies in its capacity to bring men together to fight for their health. 
"There are quite a few men who are affected by this [prostate cancer]. It's a significant problem," he said. "For Men, this is our way, for the month of November, to get together and say this is something we are going to try and fight."
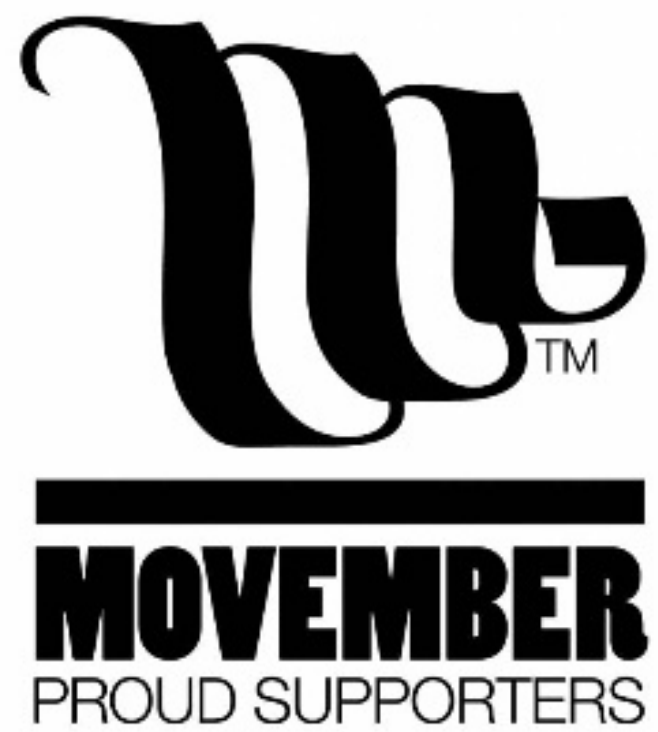

\section{“There's a bit of teasing that goes on. But it's all part of the journey."}

\section{Movember and Beyond}

Support for Movember has increased steadily in Canada. Every year, across the country, workplaces, restaurants and bars held Mo-themed galas and parties.

Between 2008 and 2009, participation jumped by 273\%. And last year, Canadians raised $\$ 7.8$ million, according to the Movember website.

The genius of Movember is that it's a fun, cheap, unique way of getting Canadians engaged in relevant men's health issues - and it's certainly amusing to supporters.

"There's a bit of embarrassment," Shah said. "There's a bit of teasing that goes on. But it's all part of the journey."

\section{Sources:}

CANCER STATS:

http://www.cancer.ca/Canada-

wide/About\%20cancer/Cancer\%20statistics/Stats\%20at\%20a\%20glance/Prostate\%20cancer.aspx?sc_lang=en\&p=1

MOVEMBER CANADA:

http://ca.movember.com/

http://ca.movemberfoundation.com/uploads/files/Foundation/Canada AR 2010.pdf

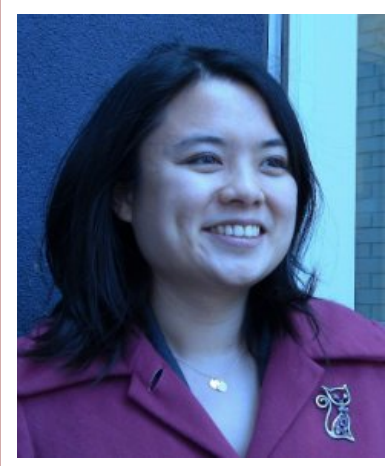

News Reporter Profile

Rebecca Cheung is a freelance journalist with degrees in Life Sciences and Physiology. She is a currently completing her graduate studies at UBC's Graduate School of Journalism. 